\title{
ACUTE MYOCARDIAL INFARCTION IN A YOUNG MALE WITH ANKYLOSING SPONDYLITIS - CASE PRESENTATION
}

\section{Ionescu Mihaela', Ionescu Paris', Peniu Luminița'2, Șuța Victoria Gristina3, Parepa Irinel-Raluca'}

${ }^{1}$ Faculty of General Medicine, "Ovidius" University of Constanta

${ }^{2}$ CF Hospital of Constanta

${ }^{3}$ Constanta County Emergency Hospital

\begin{abstract}
Cardiovascular risk scores are useful in early detecting and, most important, early correcting the cardiovascular risk factors in order to prevent the cardiovascular disease, but the most commonly used charts have essential limitations when applied to young adults.

We present the case of a 39-year-old man, known with HLA-B27-positive ankylosing spondylitis for 15 years, treated only with nonsteroidal antiinflamatory drugs, without any traditional cardiovascular risk factors, who was diagnosed with severe coronary artery disease, sub-occlusion in the proximal and midsegment of the left anterior descending artery, which required emergency percutaneous coronary intervention with drug-eluting stent implantation. In this case report we aim to highlight the necessity of considering other parameters such as C-reactive protein levels or carotid plaques when estimating the risk of developing a cardiovascular disease, especially in young adults diagnosed with chronic inflammatory disease.
\end{abstract}

Keywords: ankylosing spondylitis, myocardial infarction

\section{Introduction}

Ankylosing spondylitis (AS) is a chronic, inflammatory rheumatic disease of the sacroiliac joints and axial skeleton that usually affects young male, progressing to significant disabilities and decreased quality of life; it is also associated with elevated mortality compared with general population, largely attributable to cardiovascular disease (CVD) (1, 2). Chronic inflammation can act alone or can be linked to traditional cardiovascular (CV) risk factors, including diabetes mellitus, hypercholesterolemia, obesity, smoking or hypertension, in the early onset of atherosclerosis (3).
It is mandatory to detect early and properly treat any of these risk factors, in order to reduce CV morbidy and mortality in AS patients (4).

\section{Case Presentation}

We present the case of a 39-year-old nonsmoking man, diagnosed with HLA-B27-positive ankylosing spondylitis - grade 2 sacroiliitis at the age of 24 years, treated since then with nonsteroidal antiinflamatory drugs - etoricoxib 90 $\mathrm{mg}$ /day, currently hospitalized in the Cardiology Clinic for sharp, stabbing, recurrent chest pain in the last two weeks, correlated with emotional stress. Initially, the patient attributed the pain 
to his rheumatic disease, but then worsened in duration and frequency, causing him to present at the emergency department.

The clinical examination revealed moderate limitation of lumbar spine mobility, with normal thoracic cavity expansion, without exacerbating the pain at chest mobilization or compression. Regarding the cardiovascular system, normal blood pressure $-130 / 80 \mathrm{mmHg}$, equal in both arms, normal regular heart rate -85 beats per minute (bpm), without vascular or heart murmurs and with symmetrical peripheral pulse, normal body mass index.

The initial electrocardiogram (ECG) was performed during a pain-free period and showed sinus rhythm, $83 \mathrm{bpm}, \mathrm{QRS}$ axis at +60 degrees, symmetrical $\mathrm{T}$ waves inversion throughout the anterolateral leads (V2-V6, DI, aVL) with no Q waves and preserved $\mathrm{R}$ wave progression (Figure $1)$.

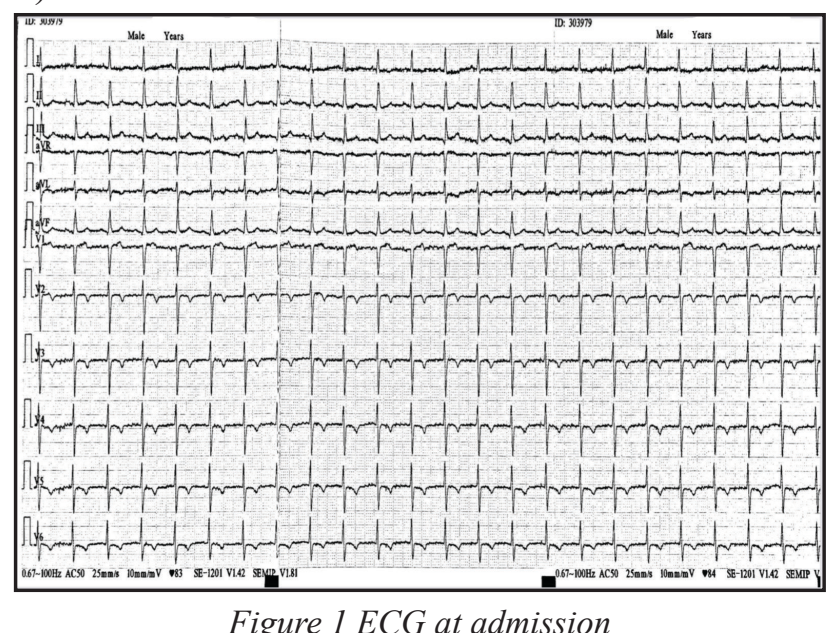

Laboratory blood tests at admission revealed elevated high-sensitivity troponin $\mathrm{T}$ (hs$\mathrm{TnT}$ ) - $167 \mathrm{pg} / \mathrm{mL}$ (normal range $<14 \mathrm{pg} / \mathrm{mL}$ ), mild hipercholesterolemia and increased levels of inflammatory markers: C-reactive protein (CRP) - $7.6 \mathrm{mg} / \mathrm{dL}$ (normal range $<0.5 \mathrm{mg} / \mathrm{dL}$ ) and erythrocyte sedimentation rate $-66 \mathrm{~mm} / \mathrm{h}$ (normal range $<15 \mathrm{~mm} / \mathrm{h}$ ); the rest of the tests being within the normal ranges.

Standard transthoracic echocardiography exposed: normal-sized heart chambers, preserved left ventricular ejection fraction of $55 \%$ (Simpson's method) with a mild hypokinesis of the interventricular septum and left ventricular apex, grade I diastolic dysfunction and mild aortic regurgitation (Figure 2A).
X-ray examination of sacroiliac joints exposes minimal sclerosis with some erosions involving a small area of the iliac and sacral bone on the left side and numerous erosions with widening of the articular gap on the right side - radiological changes specific to grade $2-3$ sacroiliitis. (Figure 2B). Chest radiograph shows a normal heart and no pleuro-pulmonary lesions.

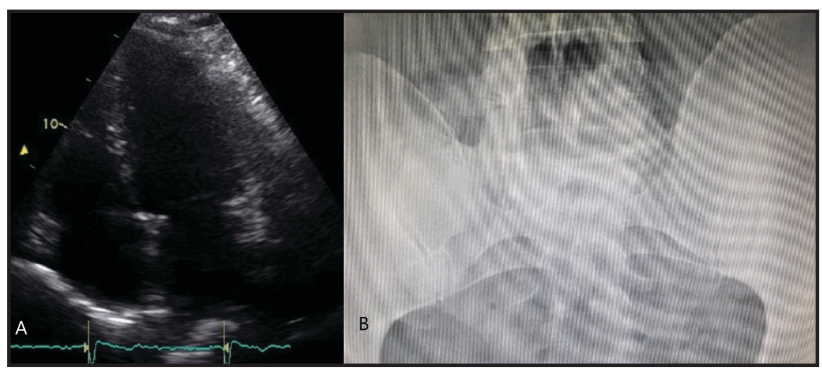

Figure 2 A-B. A. Echocardiography-apical 4 chamber view. B. Radiograph of the sacroiliac joints

Corroborating the ECG pattern with the chest pain and elevated hs-TnT, we have made the diagnosis of acute non-ST segment elevation myocardial infarction (NSTEMI), thus we initiated medical treatment with: dual antiplatelet therapy (aspirin $250 \mathrm{mg}$ and ticagrelor $180 \mathrm{mg}$ ), low molecular weight heparin (enoxaparin weight adjusted), high-dose of statin (atorvastatin $80 \mathrm{mg}$ ), beta-blocker (metoprolol $50 \mathrm{mg}$ ) and angiotensin-converting enzyme inhibitor (perindopril 2,5 mg).

Considering the diagnosis, we decided to promptly perform coronary angiography, which confirmed our suspicion, revealing subocclusion in the proximal and mid-segment of the left anterior descending (LAD) artery and also in the first septal branch (large vessel with proximal aneurysm). Percutaneous coronary intervention (PCI) with implantation of two drug-eluting stents (DES) in the proximal LAD with a kissing balloon inflation post-dilation of the septal branch; at the end of procedure a distal dissection of the LAD occurs, which is why a second stent was implanted, with a good end result (Figure 3A-B). 


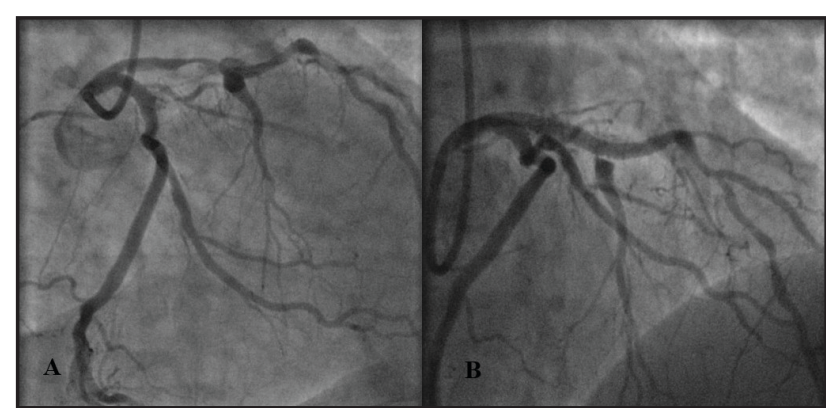

Figure 3 A-B. Coronary angiography: A. LAD before and $B$. after stents implantation.

ECG post-procedure exhibits progressive, deeply inverted $\mathrm{T}$ waves which are robust indicators of successful coronary reperfusion (Figure 4).

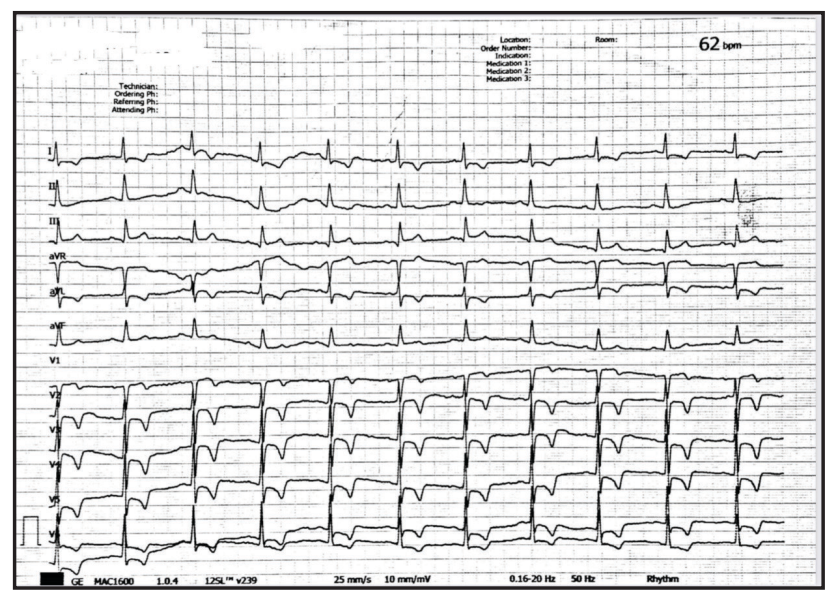

Figure 4. ECG post percutaneous coronary revascularization.

The final diagnosis of this patient was:

1. NSTEMI. Coronary artery disease sub-occlusion of the LAD artery and first septal branch. PCI and two DES implantion in midand distal LAD artery.

2. Mild aortic regurgitation. Grade I diastolic dysfunction. Hypercholesterolemia. grade 2 .

3. Ankylosindg spondytilis - sacroiliitis

\section{Discussions}

Risk scores are commonly applied in medical practice to guide agreements about primary prevention of CVD (5).

Even though significant developments have been made in recent years, CV risk scores need to be improved, especially in patients under 50 years old, and new prediction models should be developed and validated $(6,7,8)$.

Early detection and timely management of the $\mathrm{CV}$ risk factors are the key elements in preventing the $\mathrm{CV}$ disease. Most of the AS patients do not exhibit the traditional $\mathrm{CV}$ risk factors used by the standard score charts $(9,10)$. Yet, many of them are at high risk of developing $\mathrm{CV}$ disease, when we consider other parameters such as CRP levels or carotid plaques $(11,12)$.

As a result of chronic inflammation, CRP has an important role in structural damage in AS, moreover it has been associated with adverse $\mathrm{CV}$ outcome in these patients, being a more important link between AS radiological changes and CV risk than age (13).

Over time, there have been many attempts to include this marker in $\mathrm{CV}$ risk prediction models because multiple studies displayed that high plasma CRP level correlates with the severity and the extent of atherosclerosis and predicts a high risk to develop peripheral arterial disease and also of coronary events, even in apparently healthy persons (14).

Non-invasive evaluation of endothelial function of carotid arteries may also contribute to risk stratification for patients without overt CVD. This implies evaluating carotid intima-media thickness by ultrasound, which has a predictive value, especially for stoke (15).

Different combinations of risk factors interact in multiple ways, thus risk stratification can not be an exact science; they mostly change as the individual ages (in particular the predisposing factors that exacerbate the independent risk factors) (16). We must keep in mind that score risk charts are created to obtain an estimation of reality and must be interpreted in light of the physician's experience and knowledge, but nevertheless they are of real use in the medical practice.

\section{Conclusions}

This case presentation emphasizes the need for improvement of cardiovascular risk prediction models adapted to young patients diagnosed with chronic rheumatic inflammatory disease, because of the inconsistent predictive value of conventional risk factors. Future studies are necessary for the cardiovascular risk 
assessment in young adults, in order to create new prevention and intervention strategies.

\section{References}

1. Almasi S, Farahani B, Samiei N, Rezaei Y, MahmoodiH, Qorbani M. Echocardiographic and Electrocardiographic Findings in Patients with Ankylosing Spondylitis without Cardiovascular Risk Factors. J Tehran Heart Cent. 2020 Apr;15(2):43-9.

2. Valente RLM, Valente JM, de Castro GRW, Zimmermann AF, Fialho SC de MS, Pereira IA. Subclinical atherosclerosis in ankylosing spondylitis: is there a role for inflammation? Rev Bras Reumatol. 2013;53(5):377-81.

3. Ladehesa-Pineda ML, Arias de la Rosa I, López Medina C, Castro-Villegas MDC, Ábalos-Aguilera MDC, Ortega-Castro $\mathrm{R}$, et al. Assessment of the relationship between estimated cardiovascular risk and structural damage in patients with axial spondyloarthritis. Ther Adv Musculoskelet Dis. 2020;12:1759720X20982837.

4. Heslinga SC, Van den Oever IA, Van Sijl AM, Peters MJ, Van der Horst-Bruinsma IE, Smulders YM, et al. Cardiovascular risk management in patients with active Ankylosing Spondylitis: a detailed evaluation. BMC Musculoskelet Disord. 2015;16(1):80.

5. Tran D-MT, Zimmerman LM. Cardiovascular Risk Factors in Young Adults: A Literature Review. J Cardiovasc Nurs. 2015;30(4):298310.

6. Gooding HC, Gidding SS, Moran AE, Redmond N, Allen NB, Bacha F, et al. Challenges and Opportunities for the Prevention and Treatment of Cardiovascular Disease Among Young Adults: Report From a National Heart, Lung, and Blood Institute Working Group. J Am Heart Assoc. 2020 Oct;9(19):e016115.

7. George MG, Tong X, Bowman BA. Prevalence of Cardiovascular Risk Factors and Strokes in Younger Adults. JAMA Neurol. 2017 Jun;74(6):695-703.

8. Rocha E. Cardiovascular risk scores: Usefulness and limitations. Rev Port Cardiol (English Ed. 2016;35(1):15-8.
9. Wilkins JT, Lloyd-Jones DM. USPSTF Recommendations for Assessment of Cardiovascular Risk With Nontraditional Risk Factors: Finding the Right Tests for the Right Patients. Vol. 320, JAMA. United States; 2018. p. 242-4.

10. Liew JW, Ramiro S, Gensler LS. Cardiovascular morbidity and mortality in ankylosing spondylitis and psoriatic arthritis. Best Pract Res Clin Rheumatol. 2018;32(3):369-89.

11. Castro AR, Silva SO, Soares SC. The Use of High Sensitivity C-Reactive Protein in Cardiovascular Disease Detection. J Pharm Pharm Sci a Publ Can Soc Pharm Sci Soc Can des Sci Pharm. 2018;21(1):496-503.

12. MitchellC, KorcarzCE, GepnerAD, Kaufman JD, Post W, Tracy R, et al. Ultrasound carotid plaque features, cardiovascular disease risk factors and events: The Multi-Ethnic Study of Atherosclerosis. Atherosclerosis. 2018 Sep;276:195-202.

13. González Mazón I, Rueda-Gotor J, FerrazAmaro I, Genre F, Corrales A, Calvo Rio V, et al. Subclinical atherosclerotic disease in ankylosing spondylitis and non-radiographic axial spondyloarthritis. A multicenter study on 806 patients. Semin Arthritis Rheum. 2021 Apr;51(2):395-403.

14. Lagrand WK, Visser CA, Hermens WT, Niessen HW, Verheugt FW, Wolbink GJ, et al. C-reactive protein as a cardiovascular risk factor: more than an epiphenomenon? Circulation. 1999 Jul;100(1):96-102.

15. Rueda-Gotor J, Llorca J, Corrales A, Blanco R, Fuentevilla P, Portilla V, et al. Carotid ultrasound in the cardiovascular risk stratification of patients with ankylosing spondylitis: results of a population-based study. Clin Exp Rheumatol. 2016;34(5):88592.

16. Agca R, Heslinga SC, Rollefstad S, Heslinga M, McInnes IB, Peters MJL, et al. EULAR recommendations for cardiovascular disease risk management in patients with rheumatoid arthritis and other forms of inflammatory joint disorders: 2015/2016 update. Ann Rheum Dis. 2017 Jan;76(1):17-28. 